\title{
Are Adult Ureteroscopes Safe in the Management of Urolithiasis in a Pediatric Population?
}

\author{
Gregory J.Nason Rebecca Headon Matthew J. Burke Asadullah Aslam \\ Michael E. Kelly Subhasis K. Giri Hugh D. Flood \\ Department of Urology, University Hospital Limerick, Limerick, Ireland
}

\section{Key Words}

Urolithiasis • Paediatric urolithiasis • Ureteroscopy

\begin{abstract}
Introduction: Debate remains regarding the optimal caliber of ureteroscopes in the management of pediatric urolithiasis, ranging from pediatric scopes to standard scopes. The aim of this study was to assess the safety and efficacy of stone management in a pediatric population using standard adult ureteroscopes. Methods: A retrospective review of all ureteroscopic procedures in patients under the age of 16 years was carried out. Standard adult 7.5 French semi-rigid and 6 French flexible ureteroscopes were used. Results: During the study period, 8 patients underwent 21 ureteroscopic procedures. Two patients had rigid ureteroscopy, seven had flexible ureterorenoscopy and one had a subsequent open procedure. No patients required ureteric dilation. Double $\mathrm{J}$ ureteric stents were utilized in 7 patients. There were no complications. All patients required extra corporeal shock wave lithotripsy. Stone clearance was achieved in all patients. Conclusion: Our series demonstrates that, in skilled hands, adult ureteroscopes can be use safely for the treatment of urolithiasis in pediatric patients.
\end{abstract}

Copyright $\odot 2014$ S. Karger AG, Basel

KARGER

Fax +4161306 1234

E-Mail karger@karger.ch

www.karger.com
(C) 2014 S. Karger AG, Basel

1015-9770/14/0081-0026\$38.00/0

Accessible online at:

www.karger.com/cur

\section{Introduction}

Urolithiasis is less common in children than adults representing about $7 \%$ of total stones [1]. Small stones $(<$ $4 \mathrm{~mm}$ ) can be treated conservatively with medical expulsive therapy aiding spontaneous passage $[2,3]$.

The treatment of urolithiasis in pediatrics has changed with advances in technology. The advent of extracorporeal shock wave lithotripsy (ESWL) and advances in endoscopic instruments have evolved as front line treatments in patients requiring intervention [4]. Historically open surgery was required for removal of stones.

The use of ureteroscopy in a pediatric population has yet to be standardized [5]. Over the past decade there have been many advances in endoscopic equipment with the development of finer caliber instruments. Despite this there still remains debate regarding the use of age and size standardized ureteroscopes. There are still many controversies associated with the use of adult rigid ureteroscopes in a pediatric setting as it can lead to potential complications such as ureteric trauma, ischemia, and formation of stenosis and development of vesicoureteral reflux as a result of dilatation of narrow ureteric orifices [6-8]. Coupled with this, the use of balloon dilation has been suggested as routine practice prior to the use of a rigid ureteroscope in children [6].

The aim of this study was to assess the safety and efficacy of the management of urolithiasis in a pediatric population using standard adult ureteroscopes.

Gregory Nason

Department of Urology, University Hospital Limerick

Dooradoyle, Limerick

E-mail nasong@tcd.ie 


\section{Methods}

A retrospective chart review of pediatric patients who underwent ureteroscopic procedures was performed. Patients were identified from the HIPE database. Demographics recorded included age, sex, biochemical stone profile, family history, metabolic disorders and concomitant infection. All radiological imaging was reviewed to assess stone position, stone size and stone clearance. The imaging modalities utilized included plain radiography, ultrasonography, intravenous ureterography and non-contrast computed tomography. Patients routinely are screened for metabolic abnormalities.

All ureteroscopic procedures are carried out under general anesthetic in the lithotomy position with antibiotic prophylaxis. It is not standard practice in the unit to perform ureteric dilatation. A 0.038 inch standard sensor tip guide wire is routinely inserted to the affected ureteric orifice prior to navigating the ureter. Six French flexible Wolf ${ }^{\circledR}$ ureterorenoscopes and 7.5 French semi rigid $\mathrm{Wolf}^{\circledR}$ ureteroscopes were used. To minimize intra-operative heat loss, the irrigation fluid was warmed to body temperature. Decision to insert a double J ureteric stent was made by the operating surgeon depending on the duration of procedure, the degree of ureteric edema and extent of manipulation.

ESWL is carried out on an outpatient basis in a day case unit either with the patient conscious or under general anesthetic depending on age and patients ability to tolerate the procedure. Stone clearance was confirmed by absence of stone fragments on follow-up imaging (plain radiograph of kidneys, ureter, bladder or ultrasound of the kidneys).

Our unit is a tertiary referral university hospital, covering a catchment area of 380,000 . There are 3 practicing urologists in the unit, one of whom is sub specializes in pediatric urology.

\section{Results}

Eight patients underwent 21 ureteroscopic procedures during the study period (2000-2013). The median age was 6.5 years (range 8 months-16 years) (table 1). All patients were male. Two patients had rigid ureteroscopy, 7 had flexible ureterorenoscopy and 1 had a subsequent open procedure. Standard adult ureteroscopes were used in all patients. No patients required ureteric dilation. Double J ureteric stents were utilized in 7 patients. There were no intra- or post-operative complications. All stents were removed under general anesthesia at a mean duration of 8 weeks (range 3-12 weeks).

Five patients had documented positive urine cultures. Two patients had an abnormality on biochemical stone profile. An underlying secondary diagnosis or a positive family history of urolithiasis was not observed in any patient. All patients required further treatment in the form ESWL. Stone clearance was achieved in all patients. Three patients subsequently developed further stones. The mean follow-up of 7 discharged patients was 6 years 7 months (range 4 months- 9 years 10 months).
Table 1. Patient demographics and stone position

\begin{tabular}{|c|c|c|c|}
\hline Patient & Age & Stone position & $\begin{array}{l}\text { Diagnostic } \\
\text { modality }\end{array}$ \\
\hline 1 & $8 / 12$ & $\begin{array}{l}\text { Distal left ureteric calculus + bilateral } \\
\text { staghorn calculi }\end{array}$ & KUB \\
\hline 2 & 2 & $\begin{array}{l}\text { Distal left ureteric calculus + left staghorn } \\
\text { calculus }\end{array}$ & KUB \\
\hline 3 & 5 & Distal right ureteric calculus & CT \\
\hline 4 & 6 & Left staghorn calculus & KUB \\
\hline 5 & 7 & Right Pelviuteric junction calculus & US \\
\hline 6 & 10 & $\begin{array}{l}\text { Left renal pelvis and proximal ureteric calculi } \\
+ \text { right renal pelvis calculus }\end{array}$ & KUB \\
\hline 7 & 12 & Calculus in lower pole of left kidney & US \\
\hline 8 & 16 & Calculus in lower pole right kidney & US \\
\hline
\end{tabular}

$\mathrm{KUB}=$ Plain radiograph of kidneys, ureters, bladder; $\mathrm{CT}=$ non-contrast computed tomography of abdomen and pelvis; US = ultrasound of kidneys, ureters, bladder.

\section{Discussion}

Our retrospective case series demonstrates the safe and efficacious use of adult ureteroscopes in the management of urolithiasis in a pediatric population. Despite concerns in the literature regarding the safety of standard caliber instrumentation in naive pediatric ureters, we experienced no immediate- or long-term complications. The use of ureteric dilatation has been suggested in the literature however is not routine practice in adult or pediatric patients in our unit and was not necessary in this series. Stone clearance was achieved in all patients bar one who is still undergoing treatment.

Urolithiasis is less common in children. Treatment options include conservative treatment, shock wave lithotripsy or operative interventions. Endoscopic treatment has become a primary treatment strategy in the past 2 decades however there is no established standard of treatment. Shock wave lithotripsy is one of the primary treatment strategies of symptomatic stone disease in children due to its non-invasive nature [9-11]. However it often requires general anesthesia in children.

The improvements in endoscopic instruments over the past 2 decades have facilitated the endoscopic management of stone disease even in children [12]. Debate remains regarding the need for dilatation in a naive pediatric ureter. It has been suggested that dilating the ureter may predispose the child to vesicoureteric reflux and strictures $[5,12,13]$. Contrary to this the use of 'oversized' ureteroscopes has been postulated to risk ureteric avulsion, ischemia, perforation and stricture disease [14]. 
Furthermore, series which utilized ureteric dilation tend towards ureteric stenting, however the use of stents is controversial $[12,15]$. In our unit the use of ureteric stents is made at the time of the procedure based upon degree of manipulation and ureteric edema. We experienced no complications as a result of stenting in our series.

There are limited comparison studies regarding diameter of ureteroscopes. Atar et al. [16] compared the use of age standardized ureteroscopes (4.5 French) with adult ureteroscopes (7.5 French) in preschool age children (age $<6$ years).There was a significant improved stonefree rate in those treated with 'mini-ureteroscopes' especially in infants (78.6 vs. $92.6 \%$ ). Tanriverdi et al. [6] compared the safety and efficacy of 8 French rigid and 6.5 French semi-rigid ureteroscopes in a pediatric population (age range 2-16 years). Neither diameter nor rigidity affected the outcomes of the procedure. They reported an overall stone-free rate of $100 \%$ on follow-up. Yucel et al. [17] report successful results with a 7.5 French semi rigid ureteroscopes (same caliber as the present series) in children $>1$ year, with stone-clearance rates of $84 \%$. Similarly, there have been comparative studies in adult cohorts comparing scope rigidity and size with comparable stone clearance and complication rates [18-20].

A limitation of our study is the wide age range in this pediatric series. The caliber of instrumentation is not an impacting factor in stone-clearance rates in adults or adolescents however in younger children the debate is ongoing. The optimal diameter and rigiditet of ureteroscopes remains undetermined in the treatment of stones in younger children. There is a need for a large scale randomized trial to ascertain a gold standard.

\section{Conclusion}

In skilled hands, the use of adult ureteroscopes is feasible and safe in the management of urolithiasis in pediatric patients.

\section{References}

1 Raza A, Smith G, Moussa S, Tolley D: Ureteroscopy in the management of pediatric urinary tract calculi. J Endourol 2005;19:151158.

2 Galal EM, Fath El-Bab TK, Abdelhamid AM: Outcome of ureteroscopy for treatment of pediatric ureteral stones. J Pediatr Urol 2013;9: 476-478.

3 Van Savage JG, Palanca LG, Andersen RD, Rao GS, Slaughenhoupt BL: Treatment of distal ureteral stones in children: similarities to the American urological association guidelines in adults. J Urol 2000;164:1089-1093.

4 Lu J, Sun X, He L, Wang Y: Efficacy of extracorporeal shock wave lithotripsy for ureteral stones in children. Pediatr Surg Int 2009;25: 1109-1112.

5 Smaldone MC, Cannon GM Jr, Wu HY, Bassett J, Polsky EG, Bellinger MF, Docimo SG, Schneck FX: Is ureteroscopy first line treatment for pediatric stone disease? J Urol 2007; 178:2128-2131.

6 Tanriverdi O, Silay MS, Kendirci M, Kadihasanoglu M, Aydin M, Horasanli K, Miroglu $\mathrm{C}$ : Comparison of ureteroscopic procedures with rigid and semirigid ureteroscopes in pediatric population: does the caliber of instrument matter? Pediatr Surg Int 2010;26:733738.

7 7. Smaldone MC, Corcoran AT, Docimo SG, Ost MC: Endourological management of pediatric stone disease: present status. J Urol 2009; 181:17-28.
8 Satar N, Zeren S, Bayazit Y, Aridogan IA, Soyupak B, Tansug Z: Rigid ureteroscopy for the treatment of ureteral calculi in children. $\mathbf{J}$ Urol 2004;172:298-300.

9 Jee JY, Kim SD, Cho WY: Efficacy of extracorporeal shock wave lithotripsy in pediatric and adolescent urolithiasis. Korean J Urol 2013;54:865-869.

10 Badawy AA, Saleem MD, Abolyosr A, Aldahshoury M, Elbadry MS, Abdalla MA, Abuzeid AM: Extracorporeal shock wave lithotripsy as first line treatment for urinary tract stones in children: outcome of 500 cases. Int Urol Nephrol 2012;44:661-666.

11 Landau EH, Gofrit ON, Shapiro A, Meretyk S, Katz G, Shenfeld OZ, Golijanin D, Pode D: Extracorporeal shock wave lithotripsy is highly effective for ureteral calculi in children. J Urol 2001;165:2316-2319.

12 Tan AH, Al-Omar M, Denstedt JD, Razvi H: Ureteroscopy for pediatric urolithiasis: an evolving first line therapy. Urology 2005;65: 153-156.

13 VanDervoort K, Wiesen J, Frank R, Vento S, Crosby V, Chandra M, Trachtman H: Urolithiasis in pediatric patients: a single center study of incidence, clinical presentation and outcome. J Urol 2007;177:2300-2305.

14 14. Tiryaki T, Azili MN, Özmert S: Ureteroscopy for the treatment of ureteral stones in children: factors influencing the outcome. Urology 2013;81:1047-1051.
15 Kurzrock EA, Huffman JL, Hardy BE, Fugelso P: Endoscopic treatment of pediatric urolithiasis. J Pediatr Surg 1996;31:14131416.

16 Atar M, Sancaktutar AA, Penbegul N, Soylemez H, Bodakci MN, Hatipoglu NK, Bozkurt Y, Cakmakci S: Comparison of a $4.5 \mathrm{~F}$ semirigid ureteroscope with a $7.5 \mathrm{~F}$ rigid ureteroscope in the treatment of ureteral stones in preschool-age children. Urol Res 2012;40: 733-738.

17 Yucel S, Akin Y, Kol A, Danisman A, Guntekin E: Experience on semirigid ureteroscopy and pneumatic lithotripsy in children at a single center. World J Urol 2011;29: 719-723.

18 Yaycioglu O, Guvel S, Kilinc F, Egilmez T, Ozkardes H: Results with $7.5 \mathrm{~F}$ versus $10 \mathrm{~F}$ rigid ureteroscopes in treatment of ureteral calculi. Urology 2004;64:643-647.

19 Francesca F, Scattoni V, Nava L, Pompa P, Grasso M, Rigatti P: Failures and complications of transurethral ureteroscopy in 297 cases: conventional rigid instruments vs. small caliber semirigid ureteroscopes. Eur Urol 1995;28:112-115.

20 Geavlete P, Georgescu D, Nita G, Mirciulescu V, Cauni V: Complications of 2735 retrograde semirigid ureteroscopy procedures: a single-center experience. J Endourol 2006;20:179-185. 